\title{
HIV-related sexual decisions made by African- American adolescents living in different family structures: study from an ecodevelopmental perspective
}

This article was published in the following Dove Press journal:

HIVIAIDS - Research and Palliative Care

\author{
Ya-Huei Li' \\ Paula Cuccaro ${ }^{2}$ \\ Hua Chen' \\ Susan Abughosh' \\ Paras D Mehta ${ }^{3}$ \\ Ekere J Essien ${ }^{1,2}$
}

'Department of Pharmaceutical Health Outcomes and Policy, College of Pharmacy, University of Houston, Texas Medical Center, Houston, TX, USA; 'Department of Health Promotion and Behavioral Sciences, University of Texas School of Public Health, Houston, TX, USA; ${ }^{3}$ Department of Industrial Organizational Psychology, University of Houston, Houston, TX, USA
Correspondence: Ekere J Essien Institute of Community Health, University of Houston, Health Building 2 Suite 4054, 4849 Calhoun Road, Houston, TX 77204, USA

Tel +l 8328428393

Email Ejessien@central.uh.edu
Purpose: The purpose of this study was to explore the association between the dynamics of family structure and sexual behaviors of African-American adolescents using the ecodevelopmental theory.

Methods: This study stratified data from 1,617 African-American adolescents of the Add Health Wave I respondents with an identified family composition. It examined the associations between family structure, parenting function, and adolescents' sexual decision-making: age of first sexual intercourse, sexual initiation before age 16, and using a condom during the first and last sexual intercourse.

Results: Emotional connection between parents and children (feeling more love from the father: $\beta=0.17, P=0.0312$; feeling more love from the mother: $\beta=0.3314, P=0.0420$ ) and mothers' less permissive attitude toward adolescents' sexual experience in their teens $(\beta=0.33, P=0.0466)$ are positively associated with late age of sexual initiation of adolescents living in two-parent households. School-level factors ( $\beta=0.07, P=0.0008$ ) and the adolescents' characteristics (being older: $0.42, P=0.0002$; heterosexuality: $\beta=2.28, P=0.0091$ ) are the factors most positively related to the age of sexual initiation for those living with a single parent. Immediate social determinants, other than family factors (such as land use of immediate area [rural]: $\beta=9.84, P<0.0001$; the condition of living unit: $\beta=1.55, P=0.0011$; and safety of neighborhood: $\beta=4.46, P=0.004$ ), are related to late age of sexual initiation among those living with other relatives/alone. A higher tendency of condom use consistency was present in adolescents living with two parents compared to those living in other family structures.

Conclusion: Less parent/child connection and parent/family influence were found in AfricanAmerican adolescents living with other relatives or alone, suggesting that living with two residential parents plays an essential role in their late sexual initiation and could account for an important element to combat high HIV incidence of African-American adolescents.

Keywords: ecodevelopmental theory, African-Americans, adolescents, family structure, parenting function, sexual behaviors

\section{Introduction}

African-Americans aged 13-24 years have the highest rate of HIV and AIDS among all age and racial groups in the US. Due to lack of adequate knowledge, adolescents tend to experiment with new things, conform to peers, and hold a low-risk perception of HIV infection compared to adults with low self-perceived HIV/sexually transmitted infection (STI) risks ${ }^{1-3}$ and thus, adolescents tend to have low likelihood of testing 
for HIV. ${ }^{4}$ Although school-based interventions targeting school-age children and adolescents are aimed at increasing HIV/AIDS knowledge, increasing the likelihood of using a condom correctly, and increasing intentions to use a condom during sexual intercourse, ${ }^{5-7}$ randomized controlled trials (RCTs) showed that most of the school-based intervention programs demonstrated short-term effectiveness in modifying adolescents' sexual risk behaviors, ${ }^{5,8-10}$ suggesting that a multilevel approach is essential to maintain long-term behavior change. ${ }^{11}$ Therefore, this study examined the barriers to the long-term effectiveness of interventions through an "ecodevelopmental lens" and suggested corresponding solutions for maintenance of intervention effectiveness.

\section{Theoretical framework: the ecodevelopmental theory}

The ecodevelopmental theory, ${ }^{12,13}$ presented by Szapocznik and Coatsworth, is an extended social ecological model, ${ }^{14}$ with an emphasis on the structure, organization, integration, and function of young adults' social ecology over time. Similar to the social ecological model, the ecodevelopmental theory has a total of four domains, from the innermost to the outermost layers: microsystem, mesosystem, exosystem, and macrosystem. The theory emphasizes the crucial aspect of family function and interactions among various protective and risk processes from a developmental perspective.

In the ecodevelopmental theory, ${ }^{12,13}$ the adolescent is the center of the model, and the proximal social contexts develop the microsystem. Parents are the most fundamental element in an adolescent's behavioral development, and other proximal social contexts such as other family members, peers, and people at school tend to play an essential role in modifying the adolescent's behaviors because of the nature of development in adolescence. ${ }^{15-17}$

The interactions between parents and social contexts in the microsystem form the mesosystem, including parental monitoring and involvement in adolescents' peer affiliation, can directly ${ }^{18-20}$ and indirectly ${ }^{21,22}$ impact adolescents' behaviors.

Other factors, such as parents' socioeconomic status, which affect parenting styles and family function directly and influence the adolescent indirectly, create the exosystem. The socioeconomic issues associated with poverty are limited access to health care, housing, and HIV prevention education. The concentrated disadvantage and housing instability are associated with less social cohesion resulting in more crime and violence in the neighborhood, ${ }^{23}$ as well as adolescents' early sexual initiation, ${ }^{24}$ lower condom use, ${ }^{25}$ and higher rates of STIs. ${ }^{26}$
Finally, society, policies, and cultures around the adolescent and parents create the macrosystem. One example is that the acculturation differences between Hispanic parents and the adolescents are associated with weakened family function and put the adolescents at higher risk of substance use and HIV infection. ${ }^{27,28}$

The importance of parents and family function on adolescents' behavioral development is well depicted in previous studies. ${ }^{19,22,29-36}$ The question of whether the associations of parenting function/social contexts and adolescents' risk of contracting HIV can be modified by family structures remains. The missing information is vital to develop a sustainable intervention program, especially when an increasing trend of single-parent homes ${ }^{37,38}$ is observed and a high proportion of single mothers are supported by maternal grandmother and other female family members; ${ }^{39}$ the dynamics of family composition and interactions among biological parents and co-parents can play an essential role in modifying adolescents' sexual behaviors and risk of contracting HIV. Therefore, the objective of this study was to reveal the interactions between family structure and parenting function/social determinants that are associated with adolescents' sexual decision-making (the outcome). A total of four outcomes were examined: age at initiation of sexual experience, sexual experience by 16 years of age, condom use at the first and last sexual intercourse. This study answered questions about whether the associations between parenting function/social contexts and outcomes are modified by the composition of the family, whether different sexual decisions are related to elements in different systems, and whether the factors which are positively associated with the usage of a condom at the first sexual intercourse are the same ones associated with the usage of a condom at the last sexual intercourse.

\section{Methods}

\section{Database: the National Longitudinal Study of Adolescent to Adult Health}

This study was a retrospective cross-sectional study, using Wave I data of the National Longitudinal Study of Adolescent to Adult Health (Add Health). ${ }^{40,41}$ Add Health is a longitudinal study of the nationally representative US adolescents from 1994 to 2008 with four waves of interviews. A sample of 80 high schools and 52 middle schools was selected from the US with unequal probabilities of selection. Incorporating systematic sampling methods and implicit stratification assured that the sample was nationally representative with respect to region, urbanicity, school size, school type, and ethnicity. Add Health Wave I, including an in-school questionnaire and in- 
home interviews, was conducted when respondents were in grades 7-12 in 1994-1995. Add Health Wave II, conducted in 1996, covered the same questions of in-home interviews of Wave I and additional details, such as sun exposure and nutrition. Therefore, Waves I and II gathered adolescents' social and demographic information, as well as behavior decision-making. Add Health Wave III was collected in years 2001 and 2002 measuring the outcomes of decisionmaking, such as relationships, sexual experience, mental health, and criminal records. Add Health Wave IV collected in years 2008 and 2009, gathered longitudinal information on respondents' social, economic, and health status, and involvement of criminal justice system. All waves of Add Health were linked with pseudo identification; respondents were not identified through any information of the database. The target population of this study was African-American respondents in Wave I of Add Health.

\section{Participants}

A total of 1,619 African-American adolescents with an average age of 16.2 years (range $=11.6-21.2$ years) were in Wave I of Add Health. Two HIV-infected respondents were excluded from analysis since the cause of infection was unknown. This sample $(\mathrm{N}=1,617)$ comprised $17 \%$ of those aged $10-13$ years, $67 \%$ of those aged $14-17$ years, and $16 \%$ of those aged $\geq 18$ years. The sample was split equally by gender. A second sample was developed for further analyses. The second sample ( $\mathrm{N}=829)$ comprised only those adolescents who had initiated sexual intercourse prior to the survey.

\section{Measures and operationalization}

Predictors

Sixty survey items were used to create four systems of the theoretical framework (Table 1). For some variables measured with more than one question from Add Health ${ }^{40,41}$ (such as school-level factors), a composite measure was developed by incorporating those variables listed under the measure (Table 1). Independent variables in various systems of the ecodevelopmental theory include 11 variables in the microsystem (school-level factors, religion, peers, neighborhood, mother's love, father's love, physical condition of dwelling unit, types of dwelling unit, physical condition of neighborhood buildings, safety of living environment, and dominant land use of the immediate area); 6 variables in the mesosystem (mother's involvement, father's involvement, mother's attitude toward an adolescent having sexual experience in their teens, father's attitude toward an adolescent having sexual experience in their teens, mother's attitude toward an adolescent's birth control use, and father's attitude toward an adolescent's birth control use); 3 variables in the exosystem (mother's occupation, father's occupation, and household income); and 3 variables in the macrosystem (mother's receipt of public assistance, father's receipt of public assistance, and receipt of supplemental security income of any household members).

The Cronbach's alpha of composite measures for schoollevel factors $(\alpha=0.89)$, peers $(\alpha=0.74)$, religion $(\alpha=0.89)$ and neighborhood ( $\alpha=0.63)$, mother's love $(\alpha=0.94)$, and father's love $(\alpha=0.98)$ in the microsystem indicates high levels of internal consistency. The Cronbach's alpha of composite measures for mother's involvement ( $\alpha=0.81$ ), father's involvement ( $\alpha=0.97)$, mother's attitude toward an adolescent having sexual experience in their teens $(\alpha=0.92)$, and father's attitude toward an adolescent having sexual experience in their teens $(\alpha=0.99)$ in the mesosystem also demonstrated high internal consistency.

\section{Family structure}

Family structure was measured using the following variables: living with residential father, living with residential mother, living with grandparents, and living with others. Due to limited sample size, living with grandparents and living with others were collapsed into a single variable, resulting in three classes of family structure: living with both parents (i.e., two-residential parent household), living with a single parent (i.e., single-residential household), and other living arrangements (i.e., living with other relatives/alone).

\section{Outcome variables}

Three dichotomous and one continuous outcome were included in this study. The three dichotomous outcome variables were as follows: 1) having sexual intercourse before the first interview, 2) using a condom at first sexual intercourse, and 3) using a condom at last sexual intercourse. These variables are from single item responses in the Add Health $^{40,41}$ Wave I survey.

Age at first sexual intercourse was developed using information from Waves I, III, and IV of Add Health to reduce the proportion of missing data. The information on age at first sexual intercourse in Waves III and IV was used first because it was direct information obtained from the original questionnaires; then the information in Wave I was used for missing information in Waves III and IV with calculation using months and years of birthday and first sexual experience. The "age at first sexual intercourse" was a continuous outcome variable. Except for the age of sexual initiation, the 
Table I Sixty survey items and associated Cronbach's alpha values in each of four systems of the ecodevelopmental theory using Wave I Add Health

\begin{tabular}{|c|c|c|}
\hline Systems & Variables (questions) & Cronbach's alpha \\
\hline \multirow[t]{41}{*}{ Microsystem } & School-level factors (12 questions) & 0.89 \\
\hline & "Have you ever received an out-of-school suspension from school?" & \\
\hline & "Have you ever been expelled from school?" & \\
\hline & "How often did you have trouble: getting along with your teachers?" & \\
\hline & "How often did you have trouble: paying attention in school?" & \\
\hline & "How often did you have trouble: getting your homework done?" & \\
\hline & "How often did you have trouble: getting along with other students?" & \\
\hline & "You feel close to people at school." & \\
\hline & "You feel like you are part of your school." & \\
\hline & "Students at your school are prejudiced." & \\
\hline & "You are happy to be at school." & \\
\hline & "The teachers at your school treat students fairly." & \\
\hline & "You feel safe in school." & \\
\hline & Religion (2 questions) & 0.89 \\
\hline & "In the past 12 months, how often did you attend religious services?" & \\
\hline & "How important is religion to you?" & \\
\hline & Peer knowledge (3 questions) & 0.74 \\
\hline & "Your closest friends are quite knowledgeable about the withdrawal method of birth control." & \\
\hline & "Your closest friends are quite knowledgeable about how to use a condom correctly." & \\
\hline & "Your closest friends are quite knowledgeable about the rhythm method of birth control and when & \\
\hline & it is a 'safe' time during the month for a woman to have sex and not get pregnant." & \\
\hline & Closeness with people in the neighborhood (4 questions) & 0.63 \\
\hline & "People in this neighborhood look out for each other." & \\
\hline & "Do you usually feel safe in your neighborhood?" & \\
\hline & "On the whole, how happy are you with living in your neighborhood?" & \\
\hline & $\begin{array}{l}\text { "If, for any reason, you had to move from here to some other neighborhood, how happy or } \\
\text { unhappy would you be?" }\end{array}$ & \\
\hline & Feeling love from the mother ( 4 questions) & 0.94 \\
\hline & "Most of the time, your mother is warm and loving toward you." & \\
\hline & "You are satisfied with the way your mother and you communicate with each other." & \\
\hline & "How close do you feel to your mother?" & \\
\hline & "How much do you think your mother cares about you?" & \\
\hline & Feeling love from the father (4 questions) & 0.98 \\
\hline & "Most of the time, your father is warm and loving toward you." & \\
\hline & "You are satisfied with the way your father and you communicate with each other." & \\
\hline & "How close do you feel to your father?" & \\
\hline & "How much do you think your father cares about you?" & \\
\hline & Condition of dwelling unit (I question) & - \\
\hline & Dwelling unit type (I question) & - \\
\hline & Condition of neighborhood buildings (I question) & - \\
\hline & Safety of living environment (I question) & - \\
\hline & Dominant land use of the immediate area (I question) & - \\
\hline \multirow[t]{12}{*}{ Mesosystem } & Mother's involvement (5 questions) & $\overline{0} .81$ \\
\hline & "On a scale of $I-5$, where $I$ is low and 5 is high, how disappointed would your mother be if you & \\
\hline & did not graduate from college?" & \\
\hline & "On a scale of $\mathrm{I}-5$, where $\mathrm{I}$ is low and 5 is high, how disappointed would your mother be if you & \\
\hline & did not graduate from high school?" & \\
\hline & "Gone to a religious service or church-related event with you mother in the past 4 weeks." & \\
\hline & "Talked about your school work or grades with you mother in the past 4 weeks." & \\
\hline & "Talked about other things you are doing in school with you mother in the past 4 weeks." & \\
\hline & Father's involvement (5 questions) & 0.97 \\
\hline & $\begin{array}{l}\text { "On a scale of } \mathrm{I}-5 \text {, where I is low and } 5 \text { is high, how disappointed would your father be if you } \\
\text { did not graduate from college?" }\end{array}$ & \\
\hline & "On a scale of $\mathrm{I}-5$, where $\mathrm{I}$ is low and 5 is high, how disappointed would your father be if you & \\
\hline & did not graduate from high school?" & \\
\hline
\end{tabular}


Table I (Continued)

\begin{tabular}{|c|c|c|}
\hline Systems & Variables (questions) & Cronbach's alpha \\
\hline \multicolumn{3}{|c|}{ "Gone to a religious service or church-related event with you father in the past 4 weeks." } \\
\hline \multicolumn{3}{|c|}{ "Talked about your school work or grades with you father in the past 4 weeks." } \\
\hline \multicolumn{3}{|c|}{ "Talked about other things you are doing in school with you father in the past 4 weeks." } \\
\hline & Mother's attitude toward adolescent's sexual behavior ( 2 questions) & 0.92 \\
\hline \multicolumn{3}{|c|}{ "How would your mother feel about your having sex at this time in your life?" } \\
\hline \multicolumn{3}{|c|}{ "How would your mother feel about your use of a condom?" } \\
\hline & Father's attitude toward adolescent's sexual behavior ( 2 questions) & 0.99 \\
\hline \multicolumn{3}{|c|}{ "How would your father feel about your having sex at this time in your life?" } \\
\hline \multicolumn{3}{|c|}{ "How would your father feel about your use of a condom?" } \\
\hline & Mother's attitude toward adolescent's birth control use (I question) & _ \\
\hline & Father's attitude toward adolescent's birth control use (I question) & - \\
\hline \multirow[t]{3}{*}{ Exosystem } & Household income (I question) & - \\
\hline & Occupation of the mother (I question) & - \\
\hline & Occupation of the father (I question) & - \\
\hline \multirow[t]{3}{*}{ Macrosystem } & Mother received public assistance (I question) & - \\
\hline & Father received public assistance (I question) & - \\
\hline & Supplemental security income (I question) & - \\
\hline \multirow[t]{4}{*}{ Outcomes } & Adolescent's age at initiation of sexual experience & - \\
\hline & Adolescent had sexual experience by 16 years of age & - \\
\hline & Adolescent used a condom at first sexual intercourse & - \\
\hline & Adolescent used a condom at last sexual intercourse & - \\
\hline
\end{tabular}

Notes: “_” indicates only one question/item was used, and thus, no Cronbach's alpha is reported. Questions were directly quoted from Add Health, In-Home Questionnaire for Public-Use Data. Data from Harris et a $\mathrm{a}^{40}$; Data from Harris and Richard Udry. ${ }^{41}$

data for all variables used in this study were from Wave I as described previously.

\section{Statistical analyses}

Linear regression analysis was conducted for the continuous outcome. Logistic regression analysis was conducted for each dichotomous outcome. All analytical procedures were performed using SAS software 9.3 (SAS Institute Inc., Cary, NC, USA). The sampling weights were applied in the data analysis using PROC SURVEY procedures.

\section{Ethics statement}

This study received approval from the University of Houston Committee for the Protection of Human Subjects.

\section{Results}

A total of 1,617 African-Americans in Wave I of Add Health were retained, and their characteristics are presented in Table 2 . Approximately $2 \%$ of the target population was a sexual minority (homosexual or bisexual), and $10 \%$ of them had had HIV tests. Ten percent of the respondents who had a sexual experience contracted at least one STI. Approximately $40 \%$ of the participants who had a sexual experience used a condom at first sexual intercourse, and about the same proportion of them used a condom at last sexual intercourse. Approximately $80 \%$ of the adolescents lived with the biological mother, while $32 \%$ of them lived with the biological father. Regarding the family structures, $37 \%$ lived with two residential parents, $51 \%$ lived with a single parent, and $12 \%$ lived with other relatives or alone.

\section{Linear regression of age at first sexual intercourse}

Different independent variables associated with adolescents' late age of sexual initiation were observed for those living in different family structures. Feeling more love from the father ( $\beta=0.17, P=0.0312)$ and the mother $(\beta=0.14, P=0.0420)$ and mother's negative attitude toward the adolescent having sexual experience in their teens $(\beta=0.33, P=0.0466)$ were positively associated with late sexual initiation of adolescents living in two-parent households, while higher influence of schoollevel factors $(\beta=0.07, P=0.0008)$, heterosexuality $(\beta=2.28$, $P=0.0091$ ), and receiving supplemental security income ( $\beta=1.37, P=0.018$ ) were related to later sexual initiation of those living in single-parent households. Factors associated with immediate social contexts, such as condition of building ( $\beta=1.55, P=0.0011)$, land use of immediate area (rural: $\beta=9.84, P<0.0001$ ), and safety of neighborhood ( $\beta=4.46$, $P=0.004)$, were significantly associated with later age of initiation of those living with other relatives/alone. Unlike the positive association with adolescents living in two-parent households, feeling love from the mother was negatively 
Table 2 Demographic characteristics of African-American adolescents in Wave I of Add Health

\begin{tabular}{|c|c|c|c|c|c|}
\hline Variable & $\mathbf{N}$ & $\begin{array}{l}\text { Weighted } \\
\text { frequency }\end{array}$ & $\begin{array}{l}\text { Weighted } \\
\text { percentage (SD) }\end{array}$ & $x^{2}(d f)$ & $P$-value \\
\hline Age groups (years) & & & & $75.46(2)$ & $<0.0001$ \\
\hline $10-13$ & 253 & 562,899 & I5.44 (3.46) & & \\
\hline $14-17$ & 1,149 & $2,370,744$ & $65.04(2.06)$ & & \\
\hline$\geq 18$ & 280 & 711,498 & $19.52(2.67)$ & & \\
\hline Gender & & & & $0.01(1)$ & 0.9363 \\
\hline Female & 846 & $\mathrm{I}, 8 \mathrm{I} 7,50 \mathrm{I}$ & $49.86(1.74)$ & & \\
\hline Male & 771 & $1,827,639$ & $50.14(1.74)$ & & \\
\hline Sexual orientation & & & & $818.29(I)$ & $<0.0001$ \\
\hline Majority (heterosexual) & $\mathrm{I}, 583$ & $3,560,170$ & $97.67(0.50)$ & & \\
\hline Minority (homosexual or bisexual) & 34 & 84,970 & $2.33(0.50)$ & & \\
\hline Age at first sexual intercourse (years) & & & & $156.14(3)$ & $<0.0001$ \\
\hline$<10$ & 152 & 369,481 & $10.14(1.13)$ & & \\
\hline $10-15$ & 509 & $1,258,876$ & $34.54(2.58)$ & & \\
\hline $16-20$ & 176 & 393,246 & $10.79(1.39)$ & & \\
\hline Never had sexual intercourse & 780 & $1,623,537$ & $44.54(2.92)$ & & \\
\hline HIV test & & & & $560.64(1)$ & $<0.0001$ \\
\hline Tested & $|4|$ & 366,360 & $10.09(1.02)$ & & \\
\hline Never tested & $\mathrm{I}, 472$ & $3,269,809$ & $89.91(1.02)$ & & \\
\hline Numbers of sexually transmitted infection (STI) & & & & $450.09(3)$ & $<0.0001$ \\
\hline More than one STI & 18 & 40,852 & $1.12(0.33)$ & & \\
\hline Have one STI & 62 & 157,312 & $4.31(0.61)$ & & \\
\hline No STI & 756 & $|, 822| 7 \mid$, & $49.91(1.49)$ & & \\
\hline Never had sexual intercourse & 780 & $1,623,537$ & $44.47(1.44)$ & & \\
\hline Condom use at first intercourse & & & & $35.30(2)$ & $<0.0001$ \\
\hline Never had sexual intercourse & 780 & $\mathrm{I}, 623,537$ & $44.69(2.92)$ & & \\
\hline Used a condom & 536 & $1,223,387$ & $33.68(2.36)$ & & \\
\hline Not used a condom & 294 & 785,743 & $21.63(1.45)$ & & \\
\hline Condom use at last intercourse & & & & $32.36(2)$ & $<0.0001$ \\
\hline Never had sexual intercourse & 780 & $1,623,537$ & $45.04(1.45)$ & & \\
\hline Used a condom & 518 & $1,184,020$ & $32.85(1.42)$ & & \\
\hline Not used a condom & 308 & 809,984 & $22.39(1.84)$ & & \\
\hline Giving sex in exchange for drugs or money & & & & $952.29(1)$ & $<0.0001$ \\
\hline No & $1,58 \mid$ & $3,539,624$ & $98.17(0.42)$ & & \\
\hline Yes & 24 & 65,927 & $1.83(0.42)$ & & \\
\hline Biological mother & & & & $1028.10(2)$ & $<0.0001$ \\
\hline Not known & 26 & 74,572 & $2.05(0.4 I)$ & & \\
\hline Know & 203 & 551,897 & $15.18(1.32)$ & & \\
\hline Living with biological mother & I,386 & $3,009,647$ & $82.77(1.40)$ & & \\
\hline Biological father & & & & $137.80(2)$ & $<0.0001$ \\
\hline Not known & 194 & 501,515 & $13.82(1.29)$ & & \\
\hline Know & 817 & $1,951,062$ & $53.76(1.73)$ & & \\
\hline Living with biological father & 602 & $1,176,562$ & $32.42(2.37)$ & & \\
\hline Family structure of household & & & & $102.84(2)$ & $<0.0001$ \\
\hline Both parents in the household ${ }^{\ddagger}$ & 699 & $\mathrm{I}, 348,32 \mathrm{I}$ & $36.99(2.59)$ & & \\
\hline Single parent in the household $d^{\ddagger}$ & 771 & $\mathrm{I}, 868,598$ & $51.26(2.85)$ & & \\
\hline Other relatives or live alone & 147 & 428,222 & $11.75(1.22)$ & & \\
\hline Know how to use a condom & & & & $783.58(4)$ & $<0.0001$ \\
\hline Strongly disagree & 45 & 101,273 & $2.89(0.53)$ & & \\
\hline Disagree & 72 & 162,904 & $4.65(0.66)$ & & \\
\hline Neither agree nor disagree & 108 & 221,942 & $6.34(0.77)$ & & \\
\hline Agree & 560 & $1,267,897$ & $36.19(1.77)$ & & \\
\hline Strongly agree & 780 & $1,749,329$ & $49.93(2.33)$ & & \\
\hline
\end{tabular}

Notes: $\mathrm{N}=1,617$ observations; Rao-Scott chi-square test was performed using design-adjusted, survey-weighted; ¥residential parent(s): biological parent, adoptive parent, step-parent, foster parent, etc. 
associated with the age of sexual initiation for adolescents living with other relatives/alone ( $\beta=-0.23, P=0.0325)$; but mother's involvement was positively related to later sexual initiation for those living with other relatives/alone $(\beta=0.44$, $P=0.0383$ ). Some elements were shared by adolescents living in single-parent or two-parent households. For example, mother's positive attitude toward an adolescent's condom use was associated with early sexual initiation (singleparent household: $\beta=-0.29, P=0.0289$; two-parent household: $\beta=-0.28, P=0.0351$ ). A better condition of dwelling unit was associated with late sexual initiation of adolescents living with a single parent $(\beta=0.63, P=0.0218)$ and with other relatives/alone. However, receiving supplemental social security income had different associations with the age of sexual debut of adolescents living in different family structures: positive association with late sexual initiation of adolescents living in a single-parent household ( $\beta=1.37, P=0.018$ ), but positive association with early sexual initiation of those living with other relatives/alone $(\beta=-3.47, P=0.0446)$ (Table 3$)$.

\section{Logistic regression of sexual initiation before the first interview (mean age 16 years)}

Maternal factors associated with adolescents who had sexual initiation older than age 16 years were shared by those living with a single-parent (feeling love from the mother: $\mathrm{OR}=0.88$, $P=0.0208$; mother's negative attitude toward an adolescent having sexual experience in teens: $\mathrm{OR}=0.84, P=0.0417$ ) or two parents (feeling love from the mother: $\mathrm{OR}=0.85$, $P=0.0267$; mother's negative attitude toward an adolescent having sexual experience in teens $\mathrm{OR}=0.68 ; P=0.0005)$ in a home. Feeling the significance of religion $(\mathrm{OR}=1.17$; $P=0.0071)$ and having friends who had knowledge of sexual information ( $\mathrm{OR}=1.12 ; P=0.042)$ were related to adolescents living with two parents having sexual initiation before age 16 years. Alternatively, having friends who had knowledge of sexual information $(\mathrm{OR}=0.56 ; P=0.0361)$ was positively associated with adolescents living with other relatives/alone having sexual initiation older than 16 years. The higher

Table 3 Linear regression of age at first sexual intercourse of African-American adolescents in Wave I of Add Health

\begin{tabular}{|c|c|c|c|c|c|}
\hline System & Outcome & All & Structure I & Structure 2 & Structure 3 \\
\hline \multirow[t]{12}{*}{ Microsystem } & School-level factors & $0.05 * *$ & 0.06 & $0.07 * * *$ & 0.02 \\
\hline & Friends had knowledge of sexual information & $-0.12 *$ & 0.23 & -0.11 & $-0.21 *$ \\
\hline & Feeling love from the mother & 0.08 & $-0.23^{*}$ & 0.13 & $0.12 *$ \\
\hline & Feeling love from the father & 0.06 & 0.02 & -0.03 & $0.17 *$ \\
\hline & Dominant land use of immediate area (rural) & 0.88 & $9.84 * * * *$ & 1.30 & -1.18 \\
\hline & Dominant land use of immediate area (suburban) & 0.43 & -0.66 & 0.36 & 0.21 \\
\hline & Building (detached single-family house) & 0.32 & $-2.61 *$ & 0.43 & -0.14 \\
\hline & Building (mobile home/trailer) & 0.26 & $-3.20^{*}$ & -0.08 & 0.17 \\
\hline & Building (single-family row/town house) & 0.09 & -1.66 & -0.05 & -0.78 \\
\hline & The condition of dwelling unit & 0.21 & $1.55^{* *}$ & $0.63 *$ & -0.29 \\
\hline & Condition of neighborhood building & -0.45 & $-4.43 * * *$ & -0.58 & 0.32 \\
\hline & Safety of living environment & 0.83 & $4.46 * *$ & 0.44 & 0.08 \\
\hline \multirow[t]{3}{*}{ Mesosystem } & Mother's involvement & -0.02 & $0.44^{*}$ & -0.04 & 0.14 \\
\hline & Mother's attitude toward adolescent's use of birth control & $-0.36 * * * *$ & -0.44 & $-0.29 *$ & $-0.28^{*}$ \\
\hline & Mother's attitude toward adolescent having sexual experience in teens & 0.15 & -0.19 & 0.16 & $0.33^{*}$ \\
\hline \multirow[t]{7}{*}{ Exosystem } & Household income & $-0.00 * * *$ & -0.00 & -0.01 & -0.00 \\
\hline & Mother's occupation (none) & -0.54 & -1.44 & -0.94 & -0.07 \\
\hline & Mother's occupation (restaurant worker, personal service) & $-0.68^{*}$ & $-2.74 * *$ & -0.55 & -0.60 \\
\hline & Mother's occupation (computer specialist, office worker) & -0.62 & -2.27 & -0.45 & $-0.95 *$ \\
\hline & Father's occupation (none) & -0.52 & -3.33 & -2.19 & -0.66 \\
\hline & Father's occupation (restaurant worker, personal service) & -0.12 & $-2.31 *$ & 0.19 & 0.30 \\
\hline & Father's occupation (computer specialist, office worker) & 0.61 & 2.49 & 0.67 & 0.34 \\
\hline \multirow[t]{3}{*}{ Macrosystem } & Received supplemental security income & 0.87 & $-3.47^{*}$ & $1.37^{*}$ & -0.61 \\
\hline & Mother received public assistance & 0.08 & 1.70 & 0.60 & -0.95 \\
\hline & Father received public assistance & -0.63 & 0.55 & 0.91 & 0.17 \\
\hline \multirow[t]{3}{*}{ Individual } & Age & $0.43 * * *$ & 0.26 & $0.42 * * *$ & $0.40 * *$ \\
\hline & Sexual orientation (sexual majority) & $2.33^{* *}$ & 2.34 & $2.28 * *$ & 0.10 \\
\hline & Knowledge about condom use & -0.28 & $-1.43 * *$ & -0.42 & 0.00 \\
\hline$R$ square & & 0.150 & 0.69 & 0.18 & 0.17 \\
\hline
\end{tabular}

Notes: Structure I: adolescents lived with other relatives or lived alone; Structure 2: adolescents lived in a single-parent household; Structure 3: adolescents lived in a twoparent household. Sample sizes: Structure I $(\mathrm{N}=64)$, Structure $2(\mathrm{~N}=505)$, Structure $3(\mathrm{~N}=456)$, and all $(\mathrm{N}=1,025)$. $* P<0.05 ; * * P<0.01 ; * * * P<0.001 ; * * * * P<0.0001$. 
influence of school-level factors in their teens $(\mathrm{OR}=0.93$; $P=0.0019$ ) and father's negative attitude toward an adolescent having a sexual experience $(\mathrm{OR}=0.11 ; P<0.0001)$ in their teens were associated with an adolescent's first sexual experience older than 16 years among those living with a single parent (Table 4 ).

\section{Logistic regressions of condom use at first and last sexual intercourse}

No specific elements were associated with condom use at both first and last intercourse. For adolescents living in a two-parent household, higher influence of school-level factors $(\mathrm{OR}=1.05 ; P=0.0278)$, mother's negative attitude toward the adolescent having sexual experience in teens $(\mathrm{OR}=1.45$; $P=0.0086$ ), father's positive attitude toward the adolescent having sexual experience in teens $(\mathrm{OR}=0.72 ; P=0.0448)$, and living in a less safe neighborhood $(\mathrm{OR}=0.16 ; P=0.0023)$ were associated with a higher likelihood of condom use at first sexual intercourse, while having friends who had knowledge of sexual information $(\mathrm{OR}=1.37 ; P=0.0001)$, receiving supplemental security income $(\mathrm{OR}=14.16 ; P=0.0161)$, and lower influence of school-level factors $(\mathrm{OR}=0.94 ; P=0.0401)$ were associated with a higher likelihood of condom use at last sexual intercourse. For adolescents living in a singleparent household, higher influence of school-level factors $(\mathrm{OR}=1.03 ; P=0.0294)$ and acquired knowledge about condom use $(\mathrm{OR}=1.69 ; P=0.0062)$ were related to condom use at first sexual intercourse; and mother's negative attitude toward the adolescent's condom use ( $\mathrm{OR}=1.25 ; P=0.0146)$ and acquired knowledge about condom use $(\mathrm{OR}=1.75 ; P=0.0107)$ were associated with a higher likelihood of condom use at last sexual intercourse. For those living with other relatives/alone, feeling the love from the father $(\mathrm{OR}=1.68 ; P=0.0234)$ was associated with a higher likelihood of condom use at first sexual intercourse but not at last sexual intercourse (Table 5).

\section{Condom consistency at first and last sexual intercourse}

A higher proportion of adolescents living in a two-parent households used a condom at both first and last sexual intercourse $(52.45 \%)$ than those living in a single-parent household (41.29\%) or living with other relatives/alone (42.36\%). Also, a higher proportion of adolescents living in a singleparent household $(25.62 \%)$ or living with other relatives/ alone did not use a condom (24.33\%) at both first and last sexual intercourse than those living in two-parent households $(21.23 \%)$. Adolescents living with other relatives or alone tended not to use a condom at first sexual intercourse but used a condom at last sexual intercourse (19.69\%), compared to those living with a single parent $(14.45 \%)$ or two parents (12.34\%). Conversely, adolescents living in a single-parent household tended to use a condom at first sexual intercourse but did not use a condom at last sexual intercourse (18.64\%), compared to teens living in a two-parent household (13.99\%) or living with other relatives/alone (13.62\%) (Table 6).

\section{Discussion}

The current study shows that feeling love from the mother and mother's attitude toward an adolescent having sexual experience in their teens for adolescents living in a two-parent

Table 4 Logistic regression of African-American adolescents with sexual initiation prior to age of 16 years

\begin{tabular}{|c|c|c|c|c|c|}
\hline System & Variables & All & Structure I & Structure 2 & Structure 3 \\
\hline \multirow[t]{7}{*}{ Microsystem } & School-level factors & $0.96 * *$ & 0.86 & $0.93 * *$ & 1.00 \\
\hline & Significance of religion & 1.01 & 0.58 & 0.97 & $1.17^{* *}$ \\
\hline & Friends had knowledge of sexual information & 1.05 & $0.56 *$ & 1.05 & $1.12 *$ \\
\hline & Feeling love from the mother & $0.95^{*}$ & 1.26 & $0.88^{*}$ & $0.85 *$ \\
\hline & The condition of dwelling unit (very poorly kept vs. very well kept) & I.7| & 1.40 & $3.84^{*}$ & 1.66 \\
\hline & The condition of dwelling unit (poorly kept vs. very well kept) & 1.06 & 71.81 & 1.35 & 0.92 \\
\hline & The condition of dwelling unit (fairly well kept vs. very well kept) & 1.10 & 6.20 & 1.63 & 0.68 \\
\hline \multirow[t]{4}{*}{ Mesosystem } & Father's involvement & $1.12^{*}$ & 1.07 & 1.01 & 1.16 \\
\hline & Mother's attitude toward adolescent having sexual experience in teens & 0.84 & 0.42 & $0.84^{*}$ & $0.68^{* * *}$ \\
\hline & Father's attitude toward adolescent having sexual experience in teens & 0.95 & 0.63 & $0.11 * * * *$ & 0.92 \\
\hline & Mother's attitude toward adolescent's use of birth control & $1.31 * * * *$ & 1.73 & $1.35^{* *}$ & 1.15 \\
\hline \multirow[t]{3}{*}{ Individual } & Age & $1.35 * * * *$ & $2.36 * * *$ & $1.21 * *$ & $1.59 * * * *$ \\
\hline & Knowledge about condom use & $1.73 * * * *$ & $14.56 * * * *$ & $1.99 * *$ & 1.28 \\
\hline & Gender (female vs. male) & $0.70 *$ & 1.53 & $0.6 I^{*}$ & 0.88 \\
\hline C statistic & & 0.81 & 0.92 & 0.81 & 0.83 \\
\hline
\end{tabular}

Notes: Estimates are odds ratios. Target population was those who had sexual debut before the first interview of Add Health study. Structure I: adolescents lived with other relatives or lived alone; Structure 2: adolescents lived in a single-parent household; Structure 3: adolescents lived in a two-parent household. Sample sizes: Structure I $(\mathrm{N}=147)$, Structure $2(\mathrm{~N}=77 \mathrm{I})$, Structure $3(\mathrm{~N}=699)$, and all $(\mathrm{N}=1,198) . * P<0.05 ; * * P<0.01 ; * * * P<0.001 ; * * * * P<0.000 \mathrm{I}$. 


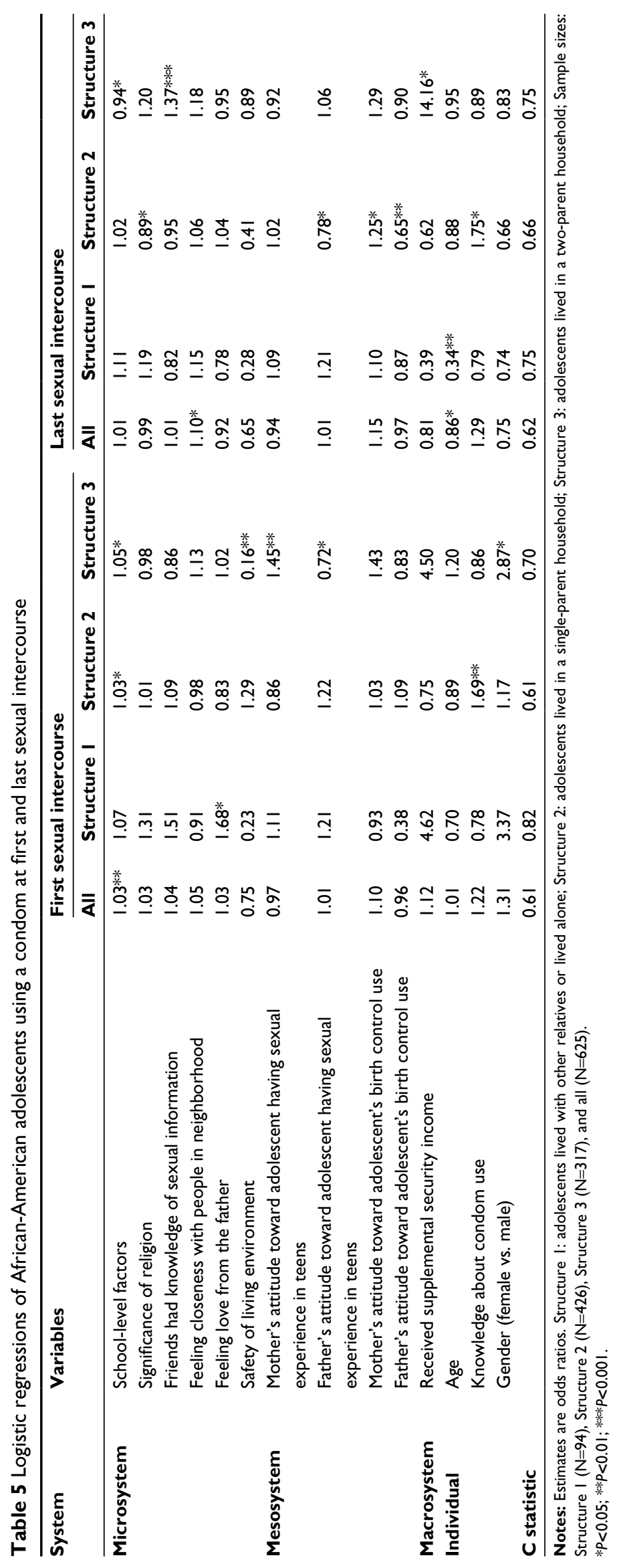


Table 6 African-American adolescents' condom use behavior at first and last sexual intercourse

\begin{tabular}{llll}
\hline Family structure & Used a condom at first sexual & Used a condom at last sexual & Percentage (SD) \\
& intercourse & No & $24.33(4.99)$ \\
\hline Structure I & No & No & $13.62(3.50)$ \\
& Yes & Yes & $19.69(4.31)$ \\
& No & Yes & $42.36(5.79)$ \\
Structure 2 & Yes & No & $25.62(2.68)$ \\
& No & No & $18.64(1.91)$ \\
Yes & No & Yes & $14.45(2.52)$ \\
Structure 3 & Yes & Yes & $41.29(2.58)$ \\
& No & No & $21.23(3.30)$ \\
& Yes & No & $13.99(2.74)$ \\
\hline
\end{tabular}

Notes: Structure I: adolescents lived with other relatives or lived alone; Structure 2: adolescents lived in a single-parent household; Structure 3: adolescents lived in a twoparent household; all participants =837; Rao-Scott chi-square $(d f)=18.15(4) ; P$-value $=0.0012$.

household are positively associated with adolescents delaying sexual initiation, while for those living in a single-parent household, other social contexts (school-level factors) and individual characteristics (sexual orientation) are associated with adolescents delaying sexual initiation. Results suggest the associations of adolescents' risk of HIV and the influence of parents and other social determinants differ by different family structures. Living with two parents, adolescents' emotional connection with parents and knowledge of mother's negative attitude toward the adolescent having a sexual experience in their teens were highly associated with adolescents' low risk of HIV. The findings support the results of Guilamo-Ramos et al's review: ${ }^{42}$ maternal factors are found to be more important than paternal factors to delay the sexual activity for African-American adolescents living in a two-parent household. Moreover, the association of school-level factors and the age of sexual initiation is significant among adolescents living with a single parent, other relatives, or alone. School-level factors and individual characteristics (e.g., age and sexual orientation) are highly associated with age of sexual initiation for those living with a single parent, while the living environment (e.g., housing in rural areas, condition of the dwelling unit, and safety of neighborhood) is associated with the age of sexual initiation for those living with other relatives or alone. Findings suggest that adolescents living in a two-parent household have a stronger connection with mothers and could benefit from the mother-child connection, and that sexually related decision-making was significantly related to individual characteristics and school-level factors among adolescents living in a single-parent household, and that immediate social contexts, which are also in the microsystem, are associated with sexually related decision making of adolescents living with other relatives/alone.

This study reveals adolescents' condom use behaviors were not associated with the same factors. For example, feeling love from the father and parents' attitude toward the adolescent's birth control use were significantly associated with condom use behavior at first sexual intercourse, while father's attitude toward the adolescent's birth control and parents' attitude toward the adolescent having a sexual experience in their teens were significantly associated with condom use behavior at last sexual intercourse. The findings support previous studies that family support and family connectedness are significantly associated with condom use consistency. ${ }^{43-47}$ Additionally, less religiosity of the young person was associated with higher risk of condomless sex at last sexual intercourse backing up previous studies pertaining to the significance of religion to the adolescent and its association with a low likelihood of risky sexual behavior. ${ }^{21}$, ${ }^{43}$ This study specified that the positive association was strong for adolescents living in a single-parent home but not for those living in other family structures. Moreover, higher connection with school-level factors was significantly related to condom use at first sexual intercourse and a risk factor of condom use at last sexual intercourse in the current study, Abebe et al. found that school attachment was a protective factor significantly associated with low risk of inconsistent condom use and multiple sexual partners. ${ }^{43}$ It is understandable that different results were presented in this study since the school-level factors in the current study comprise multiple dimensions of school factors, such as interactions between the individual-teacher and individual-other students as well as the overall atmosphere of the school. Unlike measuring 
school attachment only in Abebe et al.'s study, the influence of different school-level factors on the adolescent can be enhanced or reduced over time.

Finally, through observing condom use behavior at both first and last intercourse, this study indicates that adolescents living with two parents are more likely to use a condom consistently than those living in other family structures. This study extends the findings of Manning et al. ${ }^{48}$ that adolescents living with two biological parents tend to have condom use consistency, showing that adolescents living with two residential parents tended to have higher condom consistency than others living in other family compositions. Furthermore, this study found that adolescents living with other relatives or alone tended to use a condom at last sexual intercourse but not at first sexual intercourse, while those living with a single parent were more likely to use a condom at first sexual intercourse than at last sexual intercourse. Finally, no specific factors having the same association with condom use at both first and last sexual intercourse were identified, suggesting other elements, such as dynamics of the relationship (which was not addressed in this study), may play a role in modifying an adolescent's decision on condom use. The clinical implications are that adolescents living with other relatives or alone should be educated about the importance of condom use before sexual initiation and that those living in single-parent households should be urged to use a condom at every sexual intercourse to increase condom use consistency among those living in a household other than two-parent homes.

This study should be interpreted considering several limitations. First, the Add Health study ${ }^{40,41}$ was designed to consist of only students enrolled in school. Therefore, schoolaged children not enrolled in school were not included in the sampling design. However, it is known that those who are not enrolled in schools are likely to be at higher risk of contracting HIV due to limited exposure to information about HIV transmission. ${ }^{49,50}$ Second, the Add Health study ${ }^{40,41}$ uses self-reported measures, and, thus may be subject to social acceptability or recall bias. Finally, although several models were developed to study African-American adolescents' sexual decisions, only one wave of Add Health was used; therefore, no causal or directional inferences can be drawn from the results. Also, due to the cross-sectional study design, the family structures of adolescents might not actually reflect the change of family structures. The changes of family structure or the stability of the family structure can be an essential element influencing an adolescent's behavioral development.

Despite these limitations, there are merits to this study. First, the potential interactions between family composition and social determinants were presented with stratification by family structure. Thus, the results can be interpreted for specific subpopulations and associated clinical implications for future development of intervention programs. Second, applying the ecodevelopmental theory to examine factors in different social contexts systematically allows us to explore the potential influence of social determinants. It is essential to study the parental influence on African-American adolescents raised in singleparent, female-headed households. Finally, examining several sexual decisions of African-American adolescents provides insight into the factors associated with an adolescent's sexual behavior. The logistic regression of an adolescent's sexual experience before the first interview discloses the dynamics between family structure and social determinants at the time of the survey; the linear regression of the age of an adolescent's sexual initiation showed the potential mechanism and prompted elements that may trigger an adolescent's sexual initiation. Also, for a better understanding of an adolescent's condom use consistency, further study should focus on the influence of scenario, infection status of the partners, and situation to explore understanding of adolescents' condom use behavior.

\section{Conclusion}

We used ecodevelopmental theory and stratification by family structure to systemically examine elements from different social contexts and parental functions independently. Results show that adolescents living in a two-parent household tend to have later sexual initiation, a better sexually related health status and condom consistency than peers living in other family structures, and that factors associated with parents (such as feeling love from the parents) play a more significant role in adolescents living in a two-parent household, whereas factors associated with immediate social environment (such as feeling closeness with people in their neighborhood) are more related to those living in a single-parent household or with other relatives/alone to modify adolescents' sexual decision-making. This study provides information regarding the influence of parents and household structure on adolescents' sexual decisions to contribute to the knowledge of HIV risk among African-American adolescents.

\section{Disclosure}

The authors report no conflicts of interest in this work.

\section{References}

1. Lapsley DK, Hill PL. Subjective invulnerability, optimism bias and adjustment in emerging adulthood. JYouth Adolesc. 2010;39(8):847-857.

2. Hill PL, Duggan PM, Lapsley DK. Subjective Invulnerability, Risk Behavior, and Adjustment in Early Adolescence. J Early Adolesc. 2012;32(4):489-501. 
3. Compas BE, Connor-Smith JK, Saltzman H, Thomsen AH, Wadsworth ME. Coping with stress during childhood and adolescence: problems, progress, and potential in theory and research. Psychol Bull. 2001;127(1):87-127.

4. Adams AL, Becker TM, Lapidus JA, Modesitt SK, Lehman JS, Loveless MO. HIV infection risk, behaviors, and attitudes about testing: are perceptions changing? Sex Transm Dis. 2003;30(10):764-768.

5. Magnussen L, Ehiri JE, Ejere HO, Jolly PE. Interventions to prevent HIV/AIDS among adolescents in less developed countries: are they effective? Int J Adolesc Med Health. 2004;16(4):303-323.

6. CDC. Bringing High-Quality HIV and STD Prevention to Youth in Schools: CDC's Division of Adolescent and School Health. NPIN.CDC. GOV2014. Available from https://www.cdc.gov/healthyyouth/about/pdf/ hivstd_prevention.pdf. Accessed October 01, 2010.

7. Francis K, Philliber S, Walsh-Buhi ER, Philliber A, Seshadri R, Daley E. Scalability of an evidence-based adolescent pregnancy prevention program: new evidence from 5 cluster-randomized evaluations of the teen outreach program. Am J Public Health. 2016;106(S1):S32-S38.

8. Downs JS, Murray PJ, Bruine de Bruin W, Penrose J, Palmgren C, Fischhoff B. Interactive video behavioral intervention to reduce adolescent females' STD risk: a randomized controlled trial. Soc Sci Med. 2004;59(8):1561-1572.

9. Coyle KK, Glassman JR, Franks HM, Campe SM, Denner J, Lepore GM. Interventions to reduce sexual risk behaviors among youth in alternative schools: a randomized controlled trial. J Adolesc Health. 2013;53(1):68-78.

10. Dilorio C, Resnicow K, McCarty F, De AK, Dudley WN, Wang DT, Denzmore P. Keepin' it R.E.A.L.!: results of a mother-adolescent HIV prevention program. Nurs Res. 2006;55(1):43-51.

11. Kaufman MR, Cornish F, Zimmerman RS, Johnson BT. Health behavior change models for HIV prevention and AIDS care: practical recommendations for a multi-level approach. J Acquir Immune Defic Syndr. 2014;66(Suppl 3):S250-258.

12. Perrino T, González-Soldevilla A, Pantin H, Szapocznik J. The role of families in adolescent HIV prevention: a review. Clin Child Fam Psychol Rev. 2000;3(2):81-96.

13. Szapocznik J, Coatsworth JD. An ecodevelopmental framework for organizing the influences on drug abuse: A developmental model of risk and protection. In: Glantz MD, Hartel CR, editors. Drug Abuse: Origins \& Interventions. Washington, DC: American Psychological Association; 1999:331-366.

14. Bronfenbrenner U. The Ecology of Human Development: Experiments by Nature and Design. Cambridge: Harvard University Press; 1979.

15. Grotevant HD, Cooper CR. Individuation in family relationships: a perspective on individual differences in the development of identity and role-taking skill in adolescence. Human Development. 1986;22:82-100.

16. Maddox SJ, Prinz RJ. School bonding in children and adolescents: conceptualization, assessment, and associated variables. Clin Child Fam Psychol Rev. 2003;6(1):31-49.

17. Sieving RE, Eisenberg ME, Pettingell S, Skay C. Friends' influence on adolescents' first sexual intercourse. Perspect Sex Reprod Health. 2006;38(1):13-19.

18. Bersamin M, Todd M, Fisher DA, Hill DL, Grube JW, Walker S. Parenting practices and adolescent sexual behavior: a longitudinal study. J Marriage Fam. 2008;70(1):97-112.

19. Sieverding JA, Adler N, Witt S, Ellen J. The influence of parental monitoring on adolescent sexual initiation. Arch Pediatr Adolesc Med. 2005;159(8):724-729.

20. Sneed CD, Strachman A, Nguyen C, Morisky ED. The influence of parental monitoring and communication on adolescents sexual behavior and intentions. Vulnerable Children and Youth Studies. 2009;4:37-47.

21. Landor A, Simons LG, Simons RL, Brody GH, Gibbons FX. The role of religiosity in the relationship between parents, peers, and adolescent risky sexual behavior. J Youth Adolesc. 2011;40(3):296-309.

22. Brown BB, Mounts N, Lamborn SD, Steinberg L. Parenting practices and peer group affiliation in adolescence. Child Dev. 1993;64(2):467-482.

23. Sampson RJ, Raudenbush SW, Earls F. Neighborhoods and violent crime: a multilevel study of collective efficacy. Science. 1997;277(5328):918-924.
24. Browning CR, Leventhal T, Brooks-Gunn J. Neighborhood context and racial differences in early adolescent sexual activity. Demography. 2004;41(4):697-720.

25. Bauermeister JA, Zimmerman MA, Caldwell CH. Neighborhood disadvantage and changes in condom use among African American adolescents. J Urban Health. 2011;88(1):66-83.

26. Haley DF, Kramer MR, Adimora AA, et al. Relationships between neighbourhood characteristics and current STI status among HIV-infected and HIV-uninfected women living in the Southern USA: a cross-sectional multilevel analysis. Sex Transm Infect. 2017;93(8):583-589.

27. Bacio GA, Estrada Y, Huang S, Martínez M, Sardinas K, Prado G. Ecodevelopmental predictors of early initiation of alcohol, tobacco, and drug use among Hispanic adolescents. J Sch Psychol. 2015;53(3):195-208.

28. Farrelly C, Cordova D, Huang S, Estrada Y, Prado G. The role of acculturation and family functioning in predicting HIV risk behaviors among Hispanic delinquent youth. J Immigr Minor Health. 2013;15(3):476-483

29. Allen JP, Hauser ST, Bell KL, O'Connor TG. Longitudinal assessment of autonomy and relatedness in adolescent-family interactions as predictors of adolescent ego development and self-esteem. Child Dev. 1994;65(1):179-194.

30. Whitaker DJ, Miller KS, May DC, Levin ML. Teenage partners' communication about sexual risk and condom use: the importance of parent-teenager discussions. Fam Plann Perspect. 1999;31(3):117-121.

31. Borawski EA, Ievers-Landis CE, Lovegreen LD, Trapl ES. Parental monitoring, negotiated unsupervised time, and parental trust: the role of perceived parenting practices in adolescent health risk behaviors. J Adolesc Health. 2003;33(2):60-70.

32. Commendador KA. Parental influences on adolescent decision making and contraceptive use. Pediatr Nurs. 2010;36(3):147-156, 170.

33. Wang B, Li X, Barnett D, Zhao G, Zhao J, Stanton B. Risk and protective factors for depression symptoms among children affected by HIV/ AIDS in rural China: a structural equation modeling analysis. Soc Sci Med. 2012;74(9):1435-1443.

34. Simpkins SD, Delgado MY, Price CD, Quach A, Starbuck E. Socioeconomic status, ethnicity, culture, and immigration: examining the potential mechanisms underlying Mexican-origin adolescents' organized activity participation. Dev Psychol. 2013;49(4):706-721.

35. Adebayo AM, Ajuonu EJ, Betiku BO. Family functionality and parental characteristics as determinants of sexual decision-making of in-school youths in a semi-urban area of Southwest Nigeria. Int J Adolesc Med Health. 2016;28(4):413-418.

36. LiYH, Mgbere O, Abughosh S, Chen H, Cuccaro P, Essien JE. Modeling ecodevelopmental context of sexually transmitted disease/HIV risk and protective behaviors among African-American adolescents. HIV AIDS (Auckl). 2017;9:119-135.

37. Families and Living Arrangements, 2016. Census Bureau, US2016. Available from: https://www.census.gov/data/tables/2016/demo/families/cps-2016.html. Accessed February 20, 2018.

38. The Annie E. Casey Foundation. 2014 Kids Count Data Book. An annual report on how children are faring in the United States. Available from: http://www.aecf.org/m/resourcedoc/aecf-2014kidscountdatabook-2014. pdf. Accessed July 22, 2014.

39. Parent J, Jones DJ, Forehand R, Cuellar J, Shoulberg EK. The role of coparents in African American single-mother families: the indirect effect of coparent identity on youth psychosocial adjustment. J Fam Psychol. 2013;27(2):252-262.

40. Harris KM, Halpern CT, Whitsel E, et al. The National Longitudinal Study of Adolescent to Adult Health: Research Design2009. Available from: http://www.cpc.unc.edu/projects/addhealth/design. Accessed February 20, 2018.

41. Harris KM, and Richard UdryJ. National Longitudinal Study of Adolescent Health (Add Health), 1994-2008 (Public use). Chapel Hill, NC: Carolina Population Center, University of North Carolina-Chapel Hill/Ann Arbor: Inter-university Consortium for Political and Social Research 2014. Available from: https://www.icpsr.umich.edu/icpsrweb/ ICPSR/studies/21600. Accessed February 20, 2018. 
42. Guilamo-Ramos V, Bouris A, Lee J, McCarthy K, Michael SL, PittBarnes S, Dittus P. Paternal influences on adolescent sexual risk behaviors: a structured literature review. Pediatrics. 2012;130(5):e1313-1325.

43. Abebe M, Tsion A, Netsanet F. Living with parents and risky sexual behaviors among preparatory school students in Jimma zone, South west Ethiopia. Afr Health Sci. 2013;13(2):498-506.

44. Fentahun N, Mamo A. Risky sexual behaviors and associated factors among male and female students in Jimma Zone preparatory schools, South West Ethiopia: comparative study. Ethiop J Health Sci. 2014;24(1):59-68.

45. Ghobadzadeh M, Sieving RE, Gloppen K. Positive youth development and contraceptive use consistency. J Pediatr Health Care. 2016;30(4):308-316.

46. Jemmott LS, Jemmott JB. Family structure, parental strictness, and sexual behavior among inner-city black male adolescents. J Adolesc Res. 1992;7(2):192-207.
47. Wilson EC, Iverson E, Garofalo R, Belzer M. Parental support and condom use among transgender female youth. J Assoc Nurses AIDS Care. 2012;23(4):306-317.

48. Manning WD, Flanigan CM, Giordano PC, Longmore MA. Relationship dynamics and consistency of condom use among adolescents. Perspect Sex Reprod Health. 2009;41(3):181-190.

49. Sallar AM. Correlates of misperceptions in HIV knowledge and attitude towards people living with HIV/AIDS (PLWHAs) among in-school and out-of-school adolescents in Ghana. Afr Health Sci. 2009;9(2): 82-91.

50. Farid-ul-Hasnain S, Krantz G. Assessing reasons for school/college dropout among young adults and implications for awareness about STDs and HIV/AIDS: findings from a population-based study in Karachi, Pakistan. Int J Behav Med. 2011;18(2):122-130.
HIV/AIDS - Research and Palliative Care

\section{Publish your work in this journal}

HIV/AIDS - Research and Palliative Care is an international, peerreviewed open access journal focusing on advances in research in HIV, its clinical progression and management options including antiviral treatment, palliative care and public healthcare policies to control viral spread. The journal is included in PubMed. The manuscript man-

\section{Dovepress}

agement system is completely online and includes a very quick and fair peer-review system, which is all easy to use. Visit http://www.dovepress. com/testimonials.php to read real quotes from published authors. 